\title{
Hand Immobilizer Device
}

National Cancer Institute

\section{Source}

National Cancer Institute. Hand Immobilizer Device. NCI Thesaurus. Code C50281.

A device designed to limit the movement of the hand such as a splint for therapy or a restraint for phlebotomy. 